Dominik Rybarczyk

Andrzej Milecki

https://doi.org/10.21278/TOF.44204

ISSN 1333-1124

eISSN 1849-1391

\title{
ELECTROHYDRAULIC DRIVE WITH A FLOW VALVE CONTROLLED BY A PERMANENT MAGNET SYNCHRONOUS MOTOR
}

\begin{abstract}
Summary
This article presents an electrohydraulic drive with a new electrohydraulic flow valve controlled by a Permanent Magnet Synchronous Motor (PMSM), designed and built by the authors. In comparison to a valve with a proportional electromagnet, the use of a PMSM has enabled significant improvements in the key characteristics of the valve. A theoretical framework and a model of a PMSM are presented; subsequently, a valve with this motor is proposed and tested. Step responses of the real valve and its static and frequency characteristics are measured. The characteristics obtained in the simulation are compared with those obtained in the laboratory investigations, showing their good compliance. The obtained characteristics of the new valve are better than those of a typical proportional valve. The new valve is applied in an electrohydraulic linear actuator. For positioning tasks, two types of controllers are applied and compared: a proportional-derivative controller and a fractional order proportional-derivative controller showing satisfactory parameters.
\end{abstract}

Key words: $\quad$ electrohydraulic valve; modelling, permanent magnet synchronous motor; control

\section{Introduction}

Construction of servo valves in the early 1950s allowed the development of electrohydraulic servo drives. Nowadays, these valves are used in high-accuracy servo drives, but their application is limited due to high prices and demanding exploitation requirements. As a result, drives with servo valves are always more expensive than those with proportional ones. Proportional control valves (PCV) developed in the 1970s allowed the design of simple industrial electrohydraulic servo drives. Proportional valves are significantly cheaper but their parameters cannot match the parameters of servo valves. Nevertheless, proportional valves can satisfy the requirements in a number of industrial applications and therefore they are currently widely used. The properties and advantages of electrohydraulic servo drives and their applications are described by many authors, for example in [1-8].

A typical proportional control valve, shown in Fig. 1, consists of two DC solenoids (one for each direction), two plungers, two centring springs, a spool, and a sleeve. It has four ports: $\mathrm{A}$ and $\mathrm{B}$ (connected to the cylinder chambers), $\mathrm{P}$ (supply pressure) and T (tank). The PCV is usually an overlap type. The spool is positioned in proportion to the electrical current input to 
the solenoids. The spool movement changes the cross section areas of the working orifices, thus enabling the control of the flow to the cylinder. Responding to an electrical input signal, the proportional control valve can smoothly and continuously change the output pressure or flow.

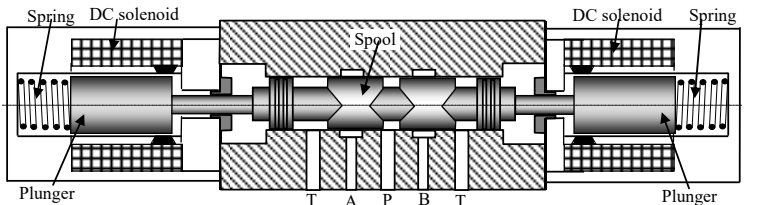

Fig. 1 Drawing of a proportional control valve with two DC solenoids

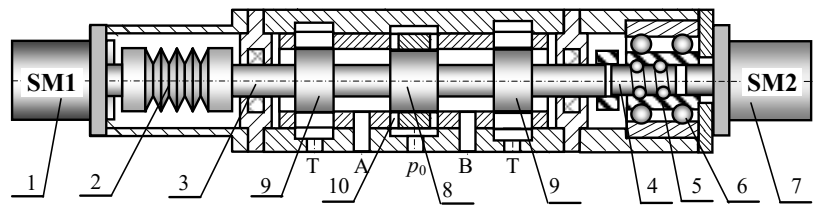

Fig. 2 Drawing of a proportional valve with two stepping motors [11]

Over the last few years, several innovations have been tested for PCVs, but no significant breakthrough has been made in their construction. The application of plastic materials [9] is an example of improvement, but the use of plastic materials in industrial applications requires further investigation. The application of piezo transducers has been investigated [10 - 12], but until now they have not been in production. As a result, proportional electromagnets are still commonly used as the driving part of PCV spools.

Another innovation in the PCV is presented in [10]. Instead of two solenoids, one stepping motor is used. This valve has been designed to obtain a very low flow, and was successfully applied in a low velocity electrohydraulic drive. The most important factor influencing the valve behaviour is the presence of contaminating particles which block the valve gaps. Taking into account that these particles usually have the shape of balls, a triangular slot in the valve body is used as the most appropriate way for passing spherical elements. The servo drive with the valve described above has obtained very low velocity, i.e. $1 \mathrm{~mm} / \mathrm{sec}$.

The use of one stepping motor may result in a key disadvantage: to fully open the valve, the motor has to make many steps, which is time consuming as it takes a few seconds. To reduce this time, the application of two stepping motors working differentially is suggested in the paper [11]. Figure 2 shows a proportional valve with two stepping motors. The stepping motor SM1 (1), attached to the valve spool (3) by the elastic coupling (2), rotates the spool joined at the end to the ball screw thread (4). This thread is seated in the nut (5) which is then attached to the stepping motor SM2 (7). The ball screw nut can rotate because it is seated inside the bearing (6) assembled in the valve housing. So, one motor drives the screw and the other drives the nut. If they are rotating in different directions, the spool linear velocity is proportional to the sum of velocities of both drives. If, on the other hand, they are rotating in the same direction but at various velocities, a very slow spool linear movement, proportional to the difference between the velocities of both drives can be obtained. The application of two stepping motors with different step angles and micro steps modes is possible as well.

\section{Electrohydraulic valve with a Permanent Magnet Synchronous Motor (PMSM)}

Due to the development of new materials and the application of modern control methods, the properties of PMSMs have significantly improved recently, making it possible to use these motors in different devices. Therefore, the application of a low-power PMSM in the electrohydraulic proportional valve is proposed in this paper, as shown in Fig. 3. On one side of this valve, a flexible coupling element (2) connects the motor (1) and the spool (3) while on the opposite side of the spool, there is a ball screw (5), the nut of which (6) is seated in the body of the valve. Rotation of the motor leads to the rotation of the spool and simultaneously to its axial - linear translation. The spool displacement $x$ is proportional to the angular displacement of the motor rotor and also to the pitch of the used thread. Direction of the spool 
translation is the same as that of the motor rotation. The spool displacement results in the opening or the closing of valve gaps in the sleeve (4). The spool with a diameter of $10 \mathrm{~mm}$ is located in the sleeve (4) in which three rectangular windows (gaps) sized $2.5 \mathrm{~mm} \times 2.0 \mathrm{~mm}$ are made for every port $(x=2.5 \mathrm{~mm}, l=2 \mathrm{~mm})$; this means that the maximum valve orifice area $A_{\max }$ is $15 \mathrm{~mm}^{2}$. The maximum spool displacement $x$ is $\pm 2.5 \mathrm{~mm}$.

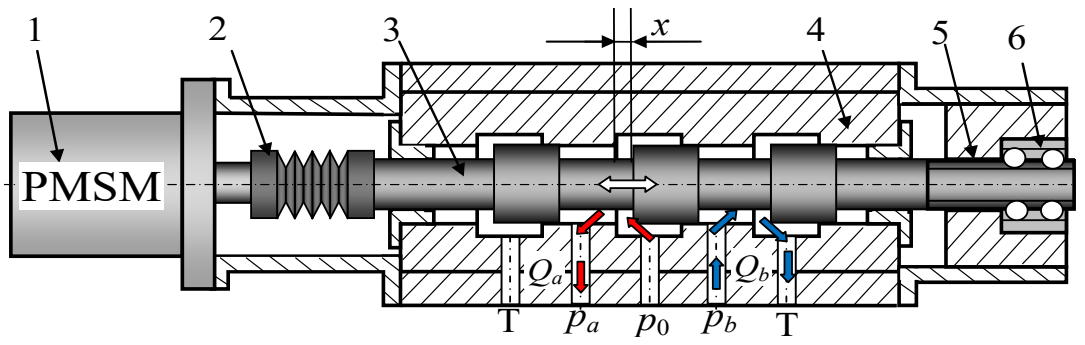

Fig. 3 Drawing of a proportional valve controlled by a PMSM (called a PMSM valve)

PMSM is a rotating electric machine with a 3-phase stator and with a rotor on which permanent magnets like $\mathrm{NdFeB}$ or SmCo are mounted. In the valve presented in Fig. 3, the low-power PMSM is applied; its basic parameters are: power - $105 \mathrm{~W}$, rated speed $3000 \mathrm{rpm}$, and nominal torque $-0.65 \mathrm{Nm}$. The motor is equipped with an absolute encoder, which generates 21600 pulses per revolution. Thus, the drive is able to move the spool with a theoretical positioning resolution of about $\pm 0.5 \mu \mathrm{m}$. The three windings on the PMSM stator are designated as $a, b$, and $c$. When they are supplied with the AC three-phase voltage, they produce a magnetic field rotating around the motor axis. The speed at which this field revolves around the centre of the machine is related to the supply frequency and the number of poles. In the steel rotor there are permanent magnets which produce a constant magnetic field. As a result of the reaction between the stator and rotor magnetic fields, the torque is acting on the rotor which rotates at the same speed as the stator field. To ensure this, a special driver should be used. To achieve smooth rotor movement, a vector control technique [12-14], also referred to as field-oriented control, is applied. In a PMSM, the stator and rotor field vectors are not orthogonal to each other. Since the windings are on the stator, it is only the current of windings that can be changed, i.e. controlled. In order develop the control system of the PMSM, the three phase currents are transformed into a two-axis system. The transformation goes from the stationary reference frame to flux and torque, at the same time producing components of the currents in the rotating reference frame. The following reference frames are used (Fig. 4):



Fig. 4 Current vectors in rotating coordinate system
1. The stator reference frame where $a, b, c$ are co-planar, distributed at every 120 degrees (red colour in Fig. 4)

2. The orthogonal reference frame in the same plane as the stator reference frame where the angle between the two axes $\alpha$ and $\beta$ is 90 degrees (blue colour). In this frame, the directions of the axes $a$ and $\alpha$ are the same.

3 . The rotor reference frame in which the $d s$ axis is located along the flux vector of the rotor (along the rotor $\mathrm{N}$ and $\mathrm{S}$ poles) and the $q s$ axis is shifted by 90 degrees relative to the $d s$ axis.

In the modelling of the PMSM, the rotating twocoordinate system, $d s-q s$, is used (Fig. 4). In this system, the relations between the supply voltage, the current, the flux, and the speed are expressed as follows [12]: 


$$
\begin{aligned}
& u_{d s}=R_{s} \cdot i_{d s}+L_{d s} \frac{\mathrm{d} \Psi_{d s}}{\mathrm{~d} t}+\Psi_{f}-\Psi_{q s} \cdot \omega \cdot \frac{p}{2} \\
& u_{q s}=R_{s} \cdot i_{q s}+L_{q s} \frac{\mathrm{d} \Psi_{q s}}{\mathrm{~d} t}-\Psi_{d s} \cdot \omega \cdot \frac{p}{2} \\
& \Psi_{d s}=L_{d s} \cdot i_{d s}+\Psi_{f} ; \quad \Psi_{q s}=L_{q s} \cdot i_{q s}
\end{aligned}
$$

where: $u_{d s}, u_{q s}, i_{d s}, i_{q s}$ - supply voltages and currents of stator windings in the $d s$ - $q s$ system, $\Psi_{d s}, \Psi_{q s}$ - stator fluxes, $L_{d s}, L_{q s}$ - inductance of stator windings in both axes, $R_{s}$ - resistance of the windings, $\omega$ - angular speed of the rotor, $p$ - number of poles, $\Psi_{f}-$ flux linkage due to the rotor.

After applying the Laplace transform to all the equations given above, they can be written in the following form:

$$
\begin{aligned}
& \Psi_{d s}(s)=\frac{1}{s L_{d s}}\left(u_{d s}-R_{s} i_{d s}(s)-\Psi_{f}(s)+\Psi_{q s}(s) \cdot \omega(s) \cdot \frac{p}{2}\right) \\
& \Psi_{q s}(s)=\frac{1}{s L_{q s}}\left(u_{q s}-R_{s} \cdot i_{q s}+\Psi_{d s} \cdot \omega \cdot \frac{p}{2}\right)
\end{aligned}
$$

The torque $T$ generated by the motor can be calculated using the following equation:

$$
T=\frac{3}{2} \cdot \frac{p}{2} \cdot\left[\psi_{f} \cdot i_{q s}+\left(L_{d s}-L_{q s}\right) \cdot i_{d s} \cdot i_{q s}\right]
$$

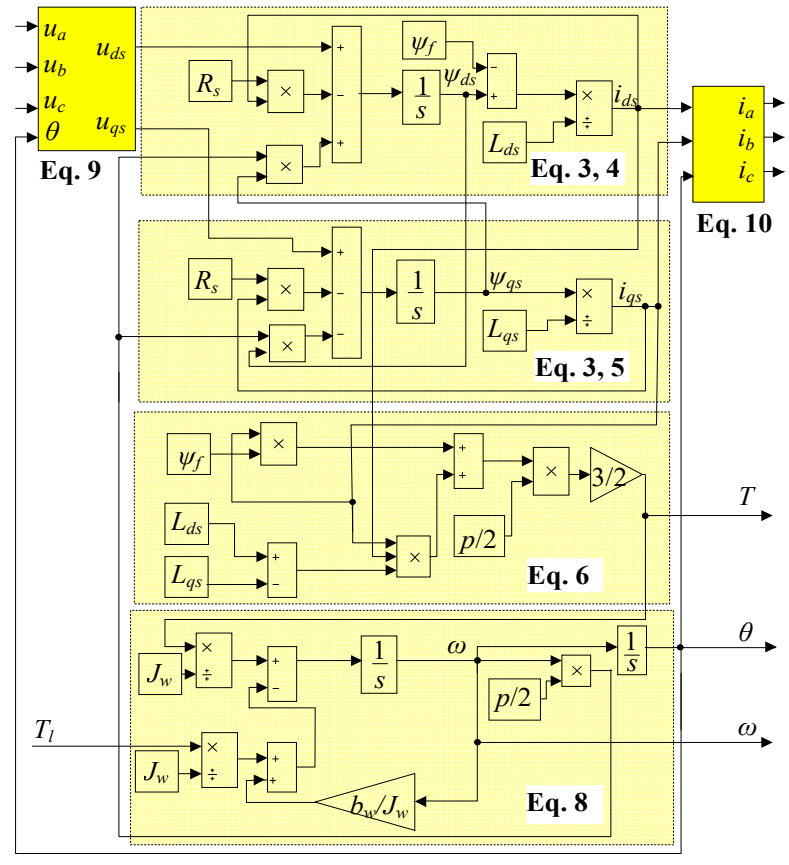

Fig. 5 A computational model of the PMSM
The mechanical dynamics of the drive can be described as follows:

$$
T=J_{w} \cdot \frac{\mathrm{d} \omega}{\mathrm{d} t}+b_{w} \omega+T_{l}
$$

where: $J_{w}$ - moment of inertia (motor rotor, valve spool, etc.), $b_{w}$ - velocity movement resistance coefficient (Newtonian friction), $T_{l}$ - load torque, mostly caused by coulombic friction and hydrodynamic forces.

This equation can be written in the following form:

$$
\frac{\mathrm{d} \omega}{\mathrm{d} t}=\frac{T}{J_{w}}-\left(\frac{b_{w}}{J_{w}} \omega+\frac{T_{l}}{J_{w}}\right) .
$$

In the motor controller, the three-phase motor input voltages $u_{a}, u_{b}$, and $u_{c}$ are changed into the two-phase quadrature voltages by using Park's transformation:

$$
\left[\begin{array}{l}
u_{q s} \\
u_{d s} \\
u_{0}
\end{array}\right]=\frac{2}{3}\left[\begin{array}{ccc}
\cos \theta & \cos (\theta-2 \pi / 3) & \cos (\theta+2 \pi / 3) \\
\sin \theta & \sin (\theta-2 \pi / 3) & \sin (\theta+2 \pi / 3) \\
0.5 & 0.5 & 0.5
\end{array}\right] \cdot\left[\begin{array}{l}
u_{a} \\
u_{b} \\
u_{c}
\end{array}\right]
$$

where: $\theta$ - rotation angle; $u_{d s}$ and $u_{q s}$ - rotating reference frame quantities, i.e. voltages in the orthogonal $d q-q s$ frame. 
The current vectors in the two-phase orthogonal system are converted into three-phase PMSM currents by using the following transformation:

$$
\left[\begin{array}{l}
i_{a} \\
i_{b} \\
i_{c}
\end{array}\right]=\left[\begin{array}{cc}
\cos \theta & \sin \theta \\
\cos (\theta-2 \pi / 3) & \sin (\theta-2 \pi / 3) \\
\cos (\theta+2 \pi / 3) & \sin (\theta+2 \pi / 3)
\end{array}\right] \cdot\left[\begin{array}{l}
i_{q s} \\
i_{d s}
\end{array}\right]
$$

where: $i_{d s}, i_{q s}$ - rotating reference frame quantities, here currents in the orthogonal $d s-q s$ frame.

Figure 5 shows a computational model of the PMSM based on equations (4)-(10). Its input signals are: the coil supply voltages $u_{a}, u_{b}$, and $u_{c}$ and the load torque $T_{l}$. The model output signals are: the coil currents $i_{a}, i_{b}$, and $i_{c}$, the generated torque $T$ and the motor rotor angular position $\theta$ and the velocity $\omega$.

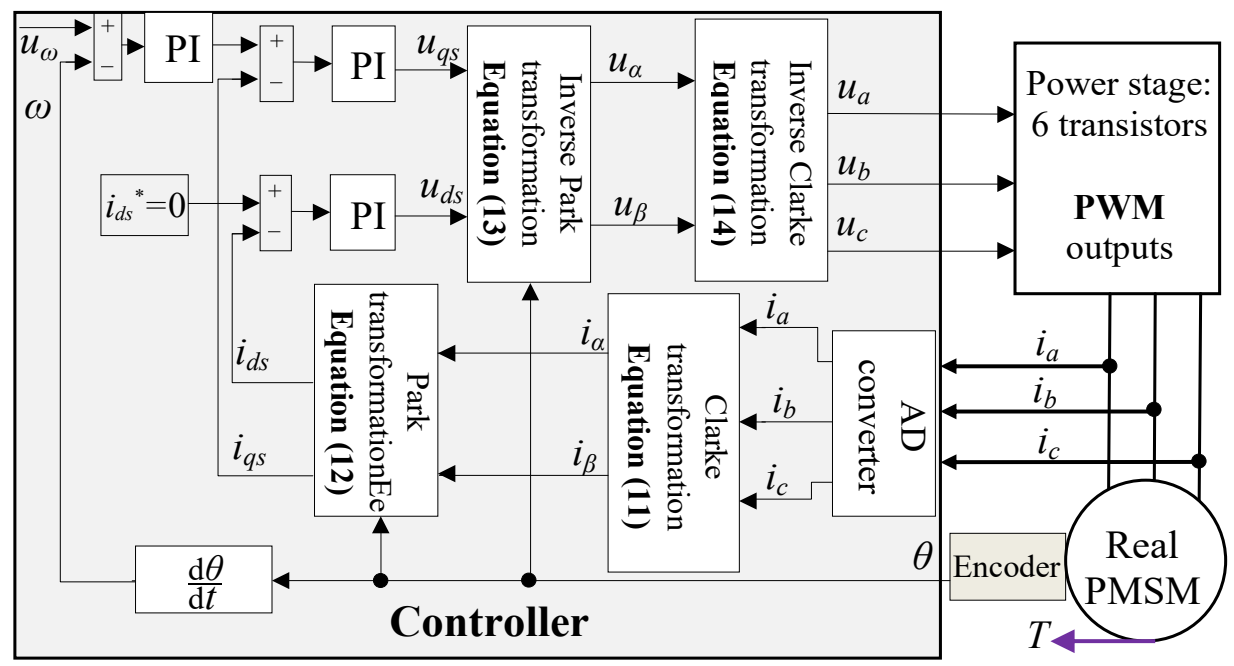

Fig. 6 A schematic of a PMSM controller structure

The PMSM controller structure is shown in Fig. 6. The assumed motor rotary speed is $u_{\omega}$. Typically, in such controllers six high power insulated gate bipolar transistors, which work in the pulse-width mode, are used in the power stage. In this controller, the measured coil currents $i_{a}, i_{b}$, and $i_{c}$ are converted from the three-phase to the two-phase currents $i_{\alpha}$ and $i_{\beta}$ by using Clarke's transformations [12]:

$$
\begin{array}{ll}
i_{d s}=i_{\alpha} \cos \theta+i_{\beta} \sin \theta & i_{\alpha}=i_{a} \\
i_{q s}=i_{\beta} \cos \theta+i_{\alpha} \sin \theta & i_{\beta}=\left(i_{a}+2 i_{b}\right) / \sqrt{3}
\end{array}
$$

where: $i_{a}+i_{b}+i_{c}=0$.

These equations transform the three-phase reference frame, in which $i_{a}, i_{b}$, and $i_{c}$ are co-planar three-phase quantities at an angle of 120 degrees to each other, to the orthogonal stationary reference frame in which $i_{\alpha}$ and $i_{\beta}$ are the current vectors perpendicular to each other, but in the same plane as the three-phase reference frame. In the next controller block, a Park's transformation is used

$$
\begin{aligned}
& i_{d s}=i_{\alpha} \cos \theta+i_{\beta} \sin \theta \\
& i_{q s}=i_{\beta} \cos \theta+i_{\alpha} \sin \theta
\end{aligned}
$$

It transforms the currents $i_{\alpha}$ and $i_{\beta}$ to a two-axis $d s-q s$ rotating coordinate system.

The currents $i_{d s}$ and $i_{q s}$ are given in two proportional integral (PI) controller inputs as feedback. These controllers compute the voltage values $u_{d s}$, and $u_{q s}$ used as inputs to the inverse Park's transformation [12], defined by the following equations: 


$$
\begin{aligned}
& u_{\alpha}=u_{d s} \cos \theta+u_{q s} \sin \theta \\
& u_{\beta}=u_{q s} \cos \theta+u_{d s} \sin \theta
\end{aligned}
$$

Finally, these voltage signals, i.e $u_{\alpha}$ and $u_{\beta}$, are back-transformed to the three-phase voltage signals $u_{a}, u_{b}$, and $u_{c}$ by using an inverse Clarke's transformation in the following form:

$$
\begin{aligned}
& u_{a}=u_{\alpha} \\
& u_{b}=\left(-u_{\alpha}+\sqrt{3} \cdot u_{\beta}\right) / 2 \\
& u_{c}=\left(-u_{\alpha}-\sqrt{3} \cdot u_{\beta}\right) / 2
\end{aligned}
$$

These signals are sent from the controller to the power system as assumed coil voltages. This stage uses the Pulse Width Modulation (PWM) method to control the power block, which typically consists of six high power transistors.

The second important element of the proportional valve is the four-edge hydraulic amplifier (see Fig. 3). Its spool (3) is located in the sleeve (4). Both of these elements form a hydraulic amplifier. The valve presented here is a zero-lapped, four-port valve with three lands. The oil flow through one orifice can be calculated as

$$
Q(t)=\mu_{d} \sqrt{2 / \rho} \cdot \sqrt{\Delta p(t)} \cdot A(t)=K_{Q} \sqrt{\Delta p(t)} \cdot x(t)
$$

where: $\Delta p$ - valve gap pressure drop (Pa), $\mu_{d}$ - valve discharge coefficient, $\rho$ - oil density $900\left(\mathrm{~kg} / \mathrm{m}^{3}\right), A$ - gap area, $x$ - spool displacement (m), $K_{Q}$ - valve flow coefficient.

The dimensionless discharge coefficient $\mu_{d}$ describes the flow losses of nozzles and orifices in the hydraulic valve. Its value mostly depends on the valve slot geometry. For the valve described in this paper, $\mu_{d}$ is assumed as 0.63 [1]. For a supply pressure of $p_{0}=32 \mathrm{MPa}$, the theoretical maximum flow of the valve described in this paper is $105 \mathrm{dm}^{3} / \mathrm{min}$. The oil flows in the valve paths can be described by the following equations $[1,4,15,16]$ :

$$
\begin{array}{ll}
\text { for: } x>0: & Q_{a}(t)=K_{Q} \sqrt{p_{0}-p_{a}(t)} \cdot x(t) \\
& Q_{b}(t)=K_{Q} \sqrt{p_{b}(t)} \cdot x(t) \\
\text { for: } x<0: & Q_{a}(t)=K_{Q} \sqrt{p_{a}(t)} \cdot x(t) \\
& Q_{b}(t)=K_{Q} \sqrt{p_{0}-p_{b}(t)} \cdot x(t)
\end{array}
$$

where: $Q_{a}-$ inlet flow, $Q_{b}$ - outlet flow; $p_{a}$ and $p_{b}$ - pressures in the actuator chambers.

In balanced spool valves, frictional and hydrodynamic forces act on the spool. The frictional forces are usually reduced by fixing a clearance of about $2-3 \mu \mathrm{m}$ between the slider and the sleeve and by introducing balancing grooves to the spool lands. Hydrodynamic forces (also called Bernoulli forces), are generated by a change in the momentum of the fluid being throttled. These forces can be calculated using the following equation $[17,18]$ :

$$
F_{h}=F_{h s t}+F_{h d}=\rho \cdot Q \cdot\left[v_{1} \cos \theta_{1}-v_{2} \cos \left(\theta_{2}+\pi\right)\right]-\rho \cdot l_{o} \frac{\partial Q}{\partial t}
$$

where: $v_{1},-$ speed of the liquid flowing into the valve, $v_{2}$ - speed of the liquid flowing out of the valve, $\theta_{1}, \theta_{2}$ - angles of inflow and outflow of the stream, $l_{o}$ - distance between gaps, $\rho$ - density of the fluid $\left(900 \mathrm{~kg} / \mathrm{m}^{3}\right)$.

The force $F_{h d}$ is called "dynamic". It is proportional to the velocity of flow change, caused by the spool movement velocity. In the valve described above, for a spool velocity of about $0.12 \mathrm{~m} / \mathrm{s}$ and a distance between gaps equal to $0.01 \mathrm{~m}$, the dynamic force can reach a value of only about $1 \mathrm{~N}$, which can be neglected. The force $F_{h s t}$ which acts on the non-moving spool is called "static". The velocity of the fluid in the gap is not directed radially but it is 
inclined at angles $\theta_{1}$ and $\theta_{2}$; the inclination changes according to the spool displacement, ranging from $50^{\circ}$ to almost $90^{\circ}$. Depending on the direction of the liquid flow, one of the angles given in equation (19) is equal to $90^{\circ}$ because in any case, one gap is the inlet or the outlet round hole. So, the force for this angle is equal to $0 \mathrm{~N}$. For basic calculation, it can be assumed that the second angle is approximately about $69^{\circ}$ relative to the spool axis. As a result, the fluid flow generates an axial force which always tends to centralise the spool. This force can be calculated as follows:

$$
F_{h s t}=\rho \cdot v \cdot Q \cdot \cos \theta=\rho \cdot \frac{Q^{2}}{A} \cos \theta=2 \cdot \mu_{d}^{2} \cdot A \cdot \Delta p \cdot \cos \theta
$$

where $\Delta p$ is the pressure drop across an orifice of the area $A$.

Assuming that $\mu_{d}=0.63$ and $\theta=69^{\circ}$, the static hydraulic force acting on the spool is

$$
F_{h s t}=0.29 \cdot A \cdot \Delta p
$$

For the valve described in this paper, the maximum value of the static hydraulic force is about $16 \mathrm{~N}\left(\Delta p=32 \mathrm{MPa}, A=1.5 \mathrm{~mm}^{2}\right)$. Taking into account that the ball screw pitch is $2.5 \mathrm{~mm} / \mathrm{rev}$ and its diameter is $10 \mathrm{~mm}$, the torque generated by the hydrodynamic force is below $0.006 \mathrm{Nm}$, which is very low in comparison to the PMSM torque which is equal to $0.65 \mathrm{Nm}$; therefore, the influence of the hydrodynamic force can be omitted.

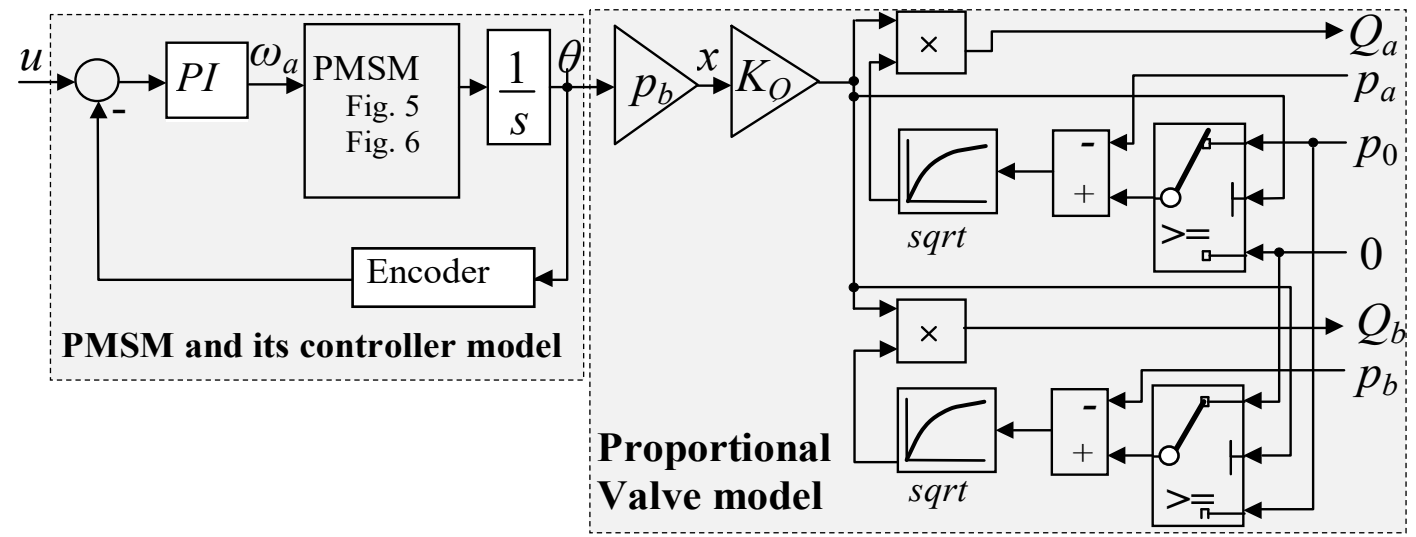

Fig. 7 A computational model of the proportional valve with a PMSM

A computational block model of the whole proportional valve with a PMSM, in which the hydraulic part (actuator) is modelled using equations (16) and (18), is shown in Fig. 7. The motor angular position is transferred to the linear displacement by a ball screw. The motor parameters are taken from its documentation and applied in the model. The model was built in the Matlab-Simulink software and used to make the simulation shown below. The parameters of all elements used in the valve model are given in Table 1.

Table 1 Valve and PMSM parameters

\begin{tabular}{|l|c|}
\hline \multicolumn{1}{|c|}{ Hydraulic parameters } & Value \\
\hline Valve flow coefficient $K_{Q}$ & 0.00018 \\
\hline Discharge coefficient $\mu_{d}$ & 0.63 \\
\hline Oil density $\rho$ & $900 \mathrm{~kg} / \mathrm{m}^{3}$ \\
\hline Spool displacement $x$ & $\pm 2.5 \mathrm{~mm}$ \\
\hline Spool diameter & $10 \mathrm{~mm}$ \\
\hline Static hydraulic force $(\Delta p=32 \mathrm{MPa})$ & $16 \mathrm{~N}$ \\
\hline $\begin{array}{l}\text { Theoretical maximum flow } \\
\left.\text { (for } p_{0}=32 \mathrm{MPa}\right)\end{array}$ & $105 \mathrm{dm}^{3} / \mathrm{min}$ \\
\hline
\end{tabular}

\begin{tabular}{|l|c|}
\hline \multicolumn{1}{|c|}{ PMSM parameters } & Value \\
\hline Power & $105 \mathrm{~W}$ \\
\hline Rated speed & $3000 \mathrm{rpm}$ \\
\hline Nominal torque & $0.65 \mathrm{Nm}$ \\
\hline $\begin{array}{l}\text { Absolute encoder } \\
\text { resolution }\end{array}$ & $\begin{array}{l}21600 \\
\text { pulses }\end{array}$ \\
\hline $\begin{array}{l}\text { Stator winding } \\
\text { inductances: } L\end{array}$ & $4.1 \mathrm{mH}$ \\
\hline Winding resistance: $R_{S}$ & $2 \mathrm{Ohm}$ \\
\hline
\end{tabular}




\section{Testing of the valve with a PMSM}

The valve with a PMSM has been built (Fig. 8) and tested in the laboratory environment. The valve was tested using a hydraulic supply pressure of $12 \mathrm{MPa}$, although it can work with a supply pressure of $32 \mathrm{MPa}$ as well. The drawings of the spool and a sleeve are shown in Fig. 9.

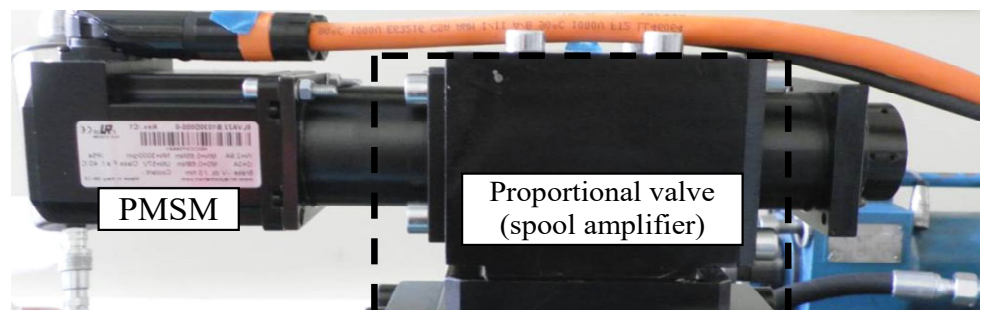

Fig. 8 Photo of the tested electrohydraulic valve with a PMSM

The hydraulic power supply unit had the following parameters: a flow rate of $70 \mathrm{dm}^{3} / \mathrm{min}$ and a maximum pressure $p_{0}$ of $32 \mathrm{MPa}$. For measurement purposes, the following sensors are used: a flow meter (with parameters: max flow $100 \mathrm{dm}^{3} / \mathrm{min}$, measurement uncertainty $0.25 \%$, and pulse output) and a pressure sensor with an accuracy of $0.3 \%$. The oil temperature during the experimental investigation ranged from $40^{\circ} \mathrm{C}$ to $50^{\circ} \mathrm{C}$.

a)

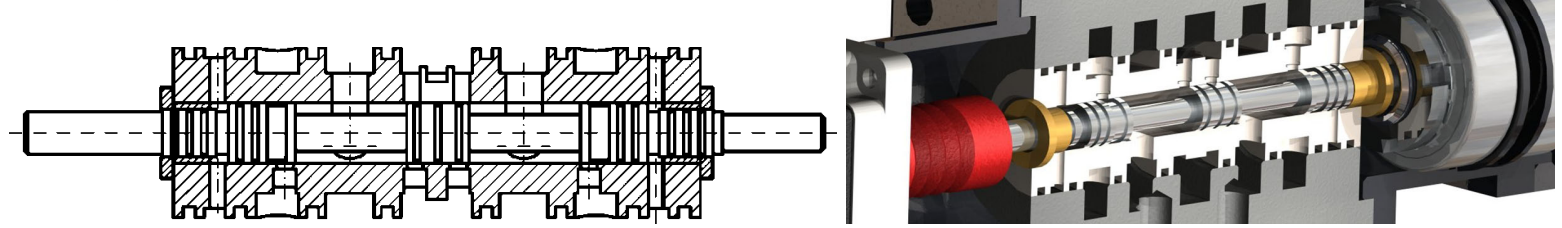

Fig. 9 Drawings of the valve spool and the sleeve: a) 2D, b) 3D



Fig. 10 Photo of a test stand with the PMSM valve connected to the flow meter

Figure 10 shows a test stand with the PMSM valve fitted. The initial tests of the valve with a PMSM showed that it is characterised by a delay of $10 \mathrm{~ms}$ and by a settling time of almost $30 \mathrm{~ms}[19,20]$. The main controller of the valve was based on a Programmable Logic Controller (PLC); the main controller worked in a multi-task real-time operating system where it was possible to set the maximum allowable task response time. By changing the response time for the spool positioning from $0.8 \mathrm{~ms}$ to $0.4 \mathrm{~ms}$ and by shortening the operation time of the real-time Ethernet communication interface between the servo controller and the main PLC to $0.2 \mathrm{~ms}$, the valve parameters were significantly improved. The valve reaction time delay was reduced from $10 \mathrm{~ms}$ to $5 \mathrm{~ms}$ and the valve spool settling time was reduced from $30 \mathrm{~ms}$ to $21 \mathrm{~ms}$ for full opening. The results, i.e. step responses of the valve with a 
PMSM and with a modified control algorithm obtained in the simulation and in laboratory tests, are presented in Fig. 11. For comparison, the step responses of a typical proportional valve with solenoids are included in the same figure [21]. The settling time $t_{s}(95 \%$ of the steady state value) of the valve with a PMSM is about $21 \mathrm{~ms}$, while the settling time of a typical proportional valve is $37 \mathrm{~ms}$ and of the valve with a stepping motor (Fig. 1) it is as much as $370 \mathrm{~ms}$ (see Fig. 12). The settling time of the direct drive valve with a linear motor is $19 \mathrm{~ms}$ [22], which is only by $2 \mathrm{~ms}$ shorter than the settling time of the valve with a PMSM. The time delay of the valve with a PMSM equal to $4 \mathrm{~ms}$ is mainly a result of the total response time of the PLC, which must perform a control program, check the current status, and handle the communications (Powerlink interface) before sending a step signal to the PMSM drive controller.

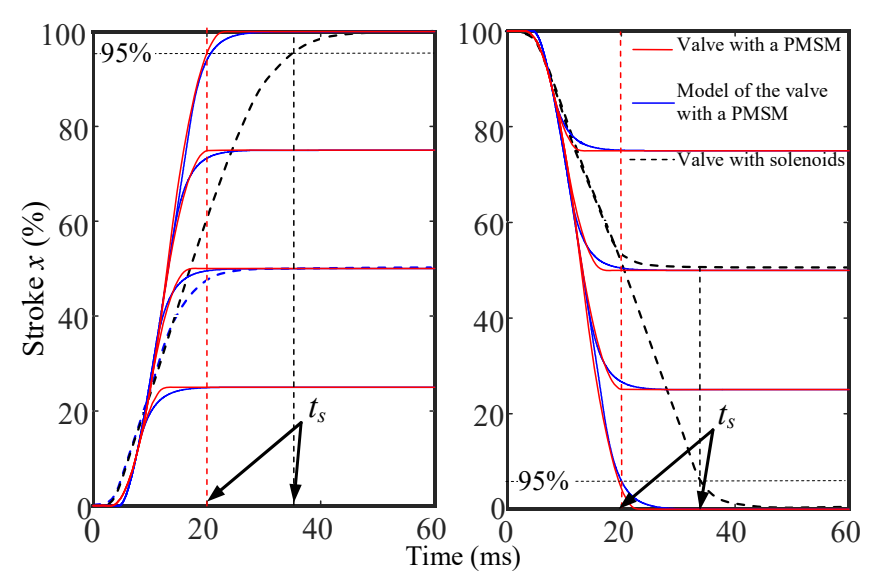

Fig. 11 PMSM valve and its model step responses $(100 \%$ is 1 rev., i.e. a displacement of $2.5 \mathrm{~mm})$

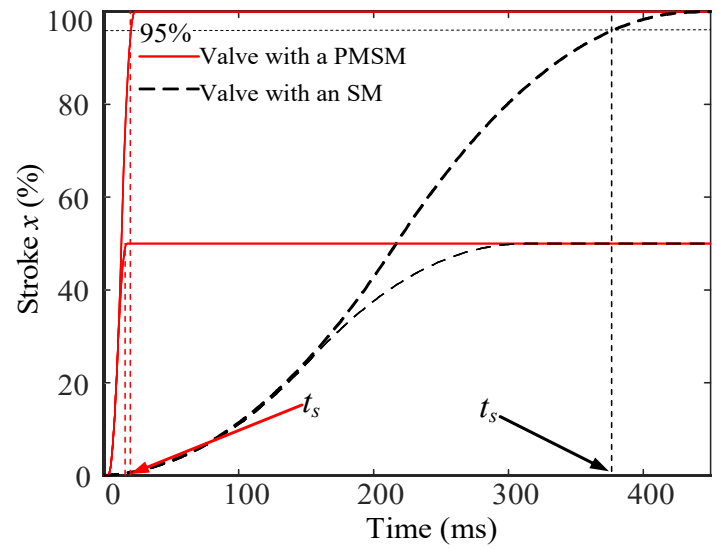

Fig. 12 Step responses of the valve with a PMSM and of that with a stepping motor (SM)

The comparison of these step responses shows that the proportional valve with a PMSM is significantly faster than the PCVs currently available on the market. It is worth noting that there is good agreement between the step response waveforms recorded in the simulation and those obtained in laboratory investigations. It shows good compatibility of the valve model with the real valve with a PMSM.

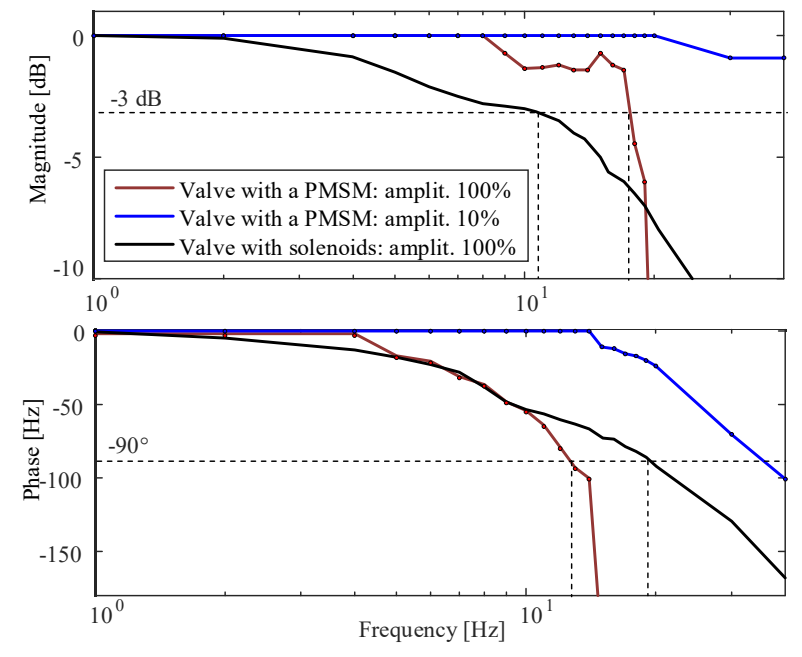

Fig. 13 Valve frequency characteristics (Bode diagrams) for amplitudes of $10 \%$ and $100 \%$

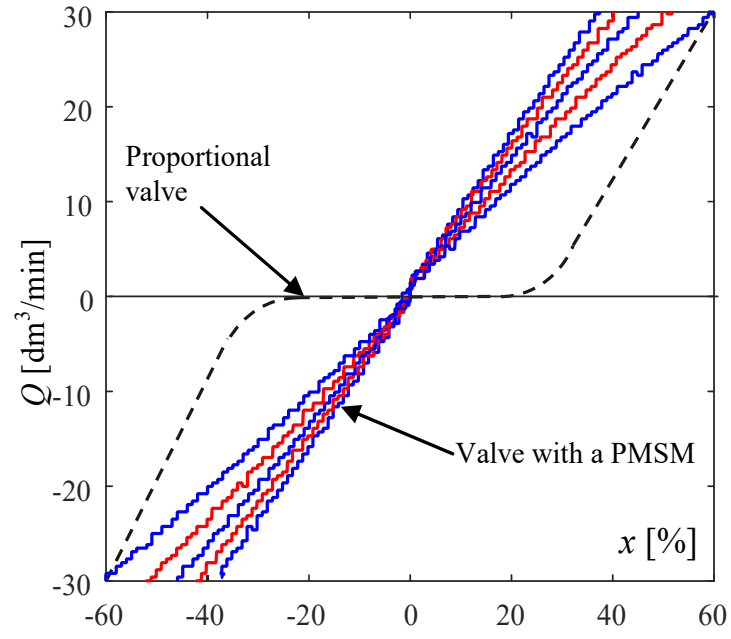

Fig. 14 Static flow characteristics of the valve with a PMSM and with a solenoid for supply pressures of 6 $\mathrm{MPa}, 8 \mathrm{MPa}, 10 \mathrm{MPa}, 12 \mathrm{MPa}$, and $14 \mathrm{MPa}$

The frequency characteristics of the valve with a PMSM obtained in laboratory tests are shown in Fig. 13. The achieved parameters for the $\pm 100 \%$ amplitude are: for the phase lag 
$90^{\circ}$, the bandwidth is $82 \mathrm{rad} / \mathrm{s}(13 \mathrm{~Hz})$, while the bandwidth for a typical proportional valve with solenoids characterised by a similar flow is $119 \mathrm{rad} / \mathrm{s}(19 \mathrm{~Hz})$; for an amplitude decrease of $3 \mathrm{~dB}$, the bandwidths are $116 \mathrm{rad} / \mathrm{s}(19 \mathrm{~Hz})$ and $11 \mathrm{~Hz}) 69 \mathrm{rad} / \mathrm{s}(11 \mathrm{~Hz})$, respectively.

The performance of the solenoid proportional valve is characterised by an important nonlinearity, i.e. the "dead zone", within which, for small current, a very weak force is generated by the electromagnet. Such a weak force is not sufficient for moving the spool. Mainly because of this, and because of the difficulties in manufacturing, only the overlapped spools(about $20 \%$ of spools) are used in proportional solenoid spool valves, which ensures reliable operation of the valve but significantly expands its dead zone. The dead zone can be only partially reduced by a simple electronic compensation. In contrast, the PMSM is able to generate the maximum output torque even for low input signals; thus, if this motor is applied in a valve, the application of the zero-lapped spool makes sense.

Figure 14 shows the static characteristic of the proportional valve with a DC electromagnet and the valve with a PMSM. One can see that the second valve is characterised by an almost linear characteristic (in the $\pm 25 \%$ range), without the dead zone. However, the static characteristics of the valve show non-linearity (saturation), which increases in the final valve openings (for maximum spool displacements). This is due to the valve inaccuracies and a drop in the supply pressure which becomes bigger for high flows. In the case of a proportional valve with a solenoid, the valve is characterised by a dead zone and therefore, the spool has to travel a distance equal to the overlap (about $20 \%$ of the maximum spool displacement) before any output flow occurs on the valve ports, giving rise to a dead zone. The theoretical maximum flow of the valve for a supply pressure of $12 \mathrm{MPa}$ is $66 \mathrm{dm}^{3} / \mathrm{min}$ and for that of $6 \mathrm{MPa}$ it is $47 \mathrm{dm}^{3} / \mathrm{min}$.

\section{Application of the valve with a PMSM in the hydraulic actuator}

The valve with a PMSM is connected to the hydraulic cylinder (Fig. 15, 16) and to the electronic controller, creating the electrohydraulic servo drive. It is controlled by another controller applied on the main PLC. For positioning tasks, two types of controllers are applied and compared: proportional-derivative (PD) and fractional order proportional-derivative (FPD) controllers. The fractional order PD controller can be described by the following formula $[23,24]$ :

$$
G_{F P D}(\mathrm{~s})=k_{p}+k_{d} \cdot s^{q}
$$

where: $k_{p}$ - gain coefficient; $k_{d}$ - derivative term; $q$ - fractional coefficients (real type number).

For the optimization of fractional order PD controller parameters, the Nelder-Mead method [25] is used; this is a numerical method for finding the minimum or the maximum of an objective function in a multidimensional space. The algorithm can have the following steps: reflection, expansion, contraction, and shrink. Structured Text and ANSI C are the languages in which the FPD algorithm is written. Due to the hardware and software implementation requirements, the fractional order continuous formula needs to be approximated by an ordinary differential equation. To this end, the Oustaloup method, described in detail in [26], is applied. The formula that is used is defined as follows:

$$
s^{q}=k \prod_{n=1}^{N} \frac{1+\frac{s}{\omega_{z n}}}{1+\frac{s}{\omega_{p n}}} \quad q>0
$$


The parameters of the equation (22) are defined as follows:

$$
\begin{aligned}
& a=\left(\frac{\omega_{h}}{\omega_{l}}\right)^{\frac{q}{N}}, \quad \eta=\left(\frac{\omega_{h}}{\omega_{l}}\right)^{\frac{1-q}{N}}, \quad \omega_{z 1}=\omega_{1} \sqrt{\eta}, \quad \omega_{z n}=\omega_{p, n-1} \eta \quad n=2, \ldots ., N \quad \text { and } \\
& \omega_{p n}=\omega_{z, n-1} a \quad n=1, \ldots ., N .
\end{aligned}
$$

where: $k$ - gain coefficient adapted in such a way that both sides have unit gains at $1 \mathrm{rad} / \mathrm{s}$, $q$ - value of fractional order (real number), $N$ - finite transfer function approximation order, $\omega_{l}-$ limit of low frequency, $\omega_{h}-$ limit of upper frequency.

A continuous controlled transfer function taken from the Oustaloup calculations is implemented in the PLC, using the ANSI C language. For approximation, the Ostaloup method is used with lower and upper frequency limits equal to $0.001 \mathrm{~Hz}$ and $1000 \mathrm{~Hz}$, respectively. The order of the finite transfer function approximation is $N=5$.

The servo drive with two controllers mentioned above is laboratory-tested. The piston position is measured using a Magnetostrictive Linear-Position Sensor (MLPS) assembled inside the cylinder (linearity deviation $0.02 \%$ ). The stroke of the hydraulic cylinder is equal to $250 \mathrm{~mm}$. The diameter of the piston is $40 \mathrm{~mm}$ and that of the piston rod $25 \mathrm{~mm}$.

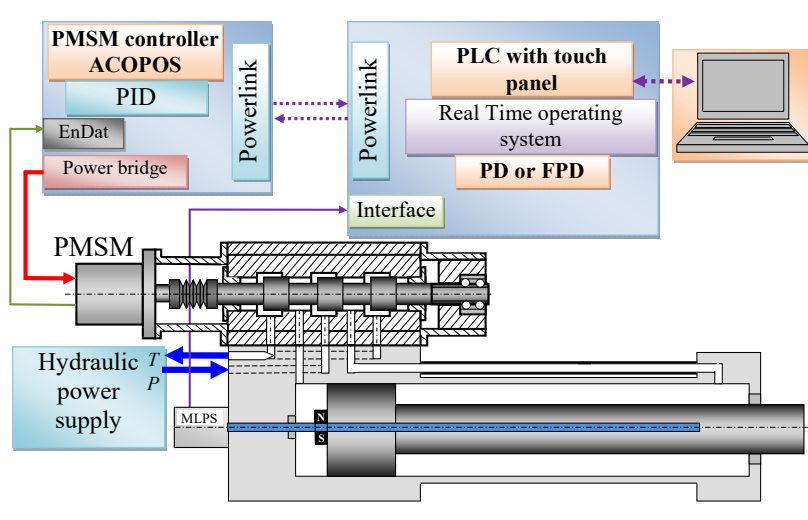

Fig. 15 The test stand block diagram



Fig. 16 Photo of the actuator with the proportional valve with a PMSM

The chosen results of recorded step responses of the servo drive with the PMSM valve for supply pressure values equal to 6 and $12 \mathrm{MPa}$ are presented in Fig. 17. These step responses are almost time delay-free. The controller parameters and the calculated Integral of the Absolute Error (IAE) measures of step responses are listed in Table 2. The best IAE values are obtained for the FPD controller.
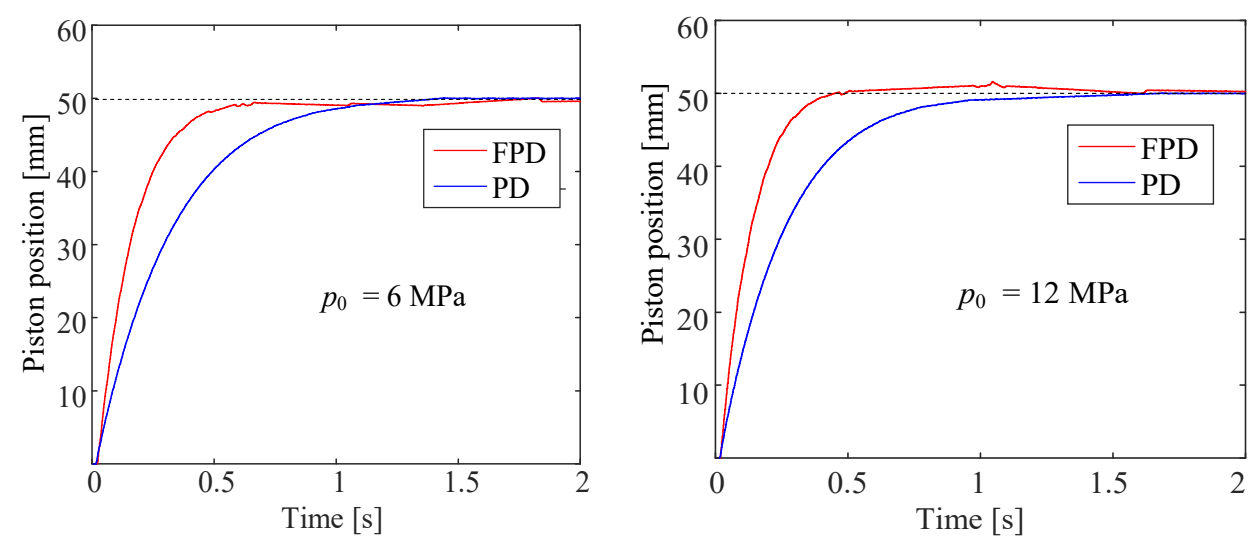

Fig. 17 Examples of step responses of electrohydraulic servo drive with a proportional valve, in which a PMSM is used, controlled by PD and fractional order PD controllers 
Table 2 Comparison between the PD and fractional order PD controllers

\begin{tabular}{|c|c|c|c|c|c|}
\hline Controller & $p_{0}[\mathrm{MPa}]$ & $k_{p}$ & $k_{d}$ & $q$ & IAE \\
\hline PD & 6 & 6 & 0.007 & 1 & 14.82 \\
\hline FPD & 6 & 8 & 0.5 & 0.9 & $\mathbf{9 . 5 9 8}$ \\
\hline PD & 12 & 6 & 0.007 & 1 & 12.410 \\
\hline FPD & 12 & 8 & 0.5 & 0.9 & $\mathbf{8 . 7 1 6}$ \\
\hline
\end{tabular}

The initial investigations have shown that the achieved positioning accuracy of the tested servo drive controlled by PD controllers is equal to $\pm 0.06 \mathrm{~mm}$.

\section{Conclusion}

The paper presents the design and the test results of an electrohydraulic proportional control valve in which a PMSM is applied. The aims of the presented research were:

- to propose a theoretical description of the electrohydraulic servo drive consisting of a PMSM with its controller, a hydraulic flow valve, and a cylinder,

- to create a model of the servo drive using the Matlab-Simulink software,

- to design, build and test a new electrohydraulic valve with a PMSM,

- to use typical PD and fractional order PD controllers in the electrohydraulic servo drive with a new valve and to conduct laboratory investigations into this drive.

The PMSM controller is described and its model is created in Matlab-Simulink; then, a model of the valve is proposed. It is used in the design phase to check up the influence of the valve parameters on step responses and to set the initial settings of the PMSM controller parameters. The new valve is built and investigated on a test stand. In this valve, the PMSM is replaced with a stepping motor and step responses of this valve are measured and also included in the paper. The obtained waveforms are compared with the results obtained in simulation and with typical proportional valve step responses. The measured settling time of the valve with a PMSM is better than the settling time of the proportional valve. Subsequently, the valve with a PMSM is applied in the electrohydraulic linear actuator and investigated. Two types of controllers, i.e. proportional-derivative (PD) and fractional order proportional-derivative (FPD) are used and compared, showing that the application of the latter controller enabled the achievement of better dynamic parameters and positioning accuracy. The application of PMSM in the valve enables simple and commonly used communication with other control devices using different interfaces, which is an advantage that simplifies a possible use of the new valve in the industrial practice. From an integration point of view, the designed valve can be treated as an electric motor and can be controlled as such, which is both easy and convenient. The device can be used in various types of precise machines where a strong force is required, for example in plastic forming or moulding machines.

\section{Acknowledgements}

This study is supported by the Polish Ministry of Science and Education with the grant no 02/22/SBAD/1501. 


\section{REFERENCES}

[1] H. E. Merritt, Hydraulic Control Systems, NY, USA, Wiley, 1967.

[2] J. Yao, W. Deng, W. Sun, Precision Motion Control for Electro-Hydraulic Servo Systems with Noise Alleviation: A Desired Compensation Adaptive Approach, IEEE/ASME Transactions on Mechatronics, vol. 22, no. 4, pp. 1859-1868, 2017. https://doi.org/10.1109/tmech.2017.2688353

[3] A. Plummer, Electrohydraulic servovalves - past, present, and future. In: 10th International Fluid Power Conference, 2016.

[4] S. J. Cundiff, Fluid Power Circuits and Control. Fundamentals and Applications, CRC Press, 2001.

[5] H. Murrenhoff, Hydraulic drives in stationary applications. In Customer benefits of fluid power, conference proceedings, 5rd International Fluid Power Conference (5th IFK), 2006.

[6] H. Murrenhoff, Trends in Valve Development, Ölhydraulik und Pneumatik, vol. 46, 4, 2003.

[7] S. Alfayad, F.B. Ouezdou, F. Namoun, G. Gheng, High performance integrated electro-hydraulic actuator for robotics - Part I: Principle, prototype design and first experiments, Sensors and Actuators A: Physical, Vol. 169, Issue 1, p. 124-132, 2011. https://doi.org/10.1016/j.sna.2010.10.026

[8] Koreck, J. \& von Estorff, O., Reduced order structural models for the calculation of wet contact forces due to impacts in hydraulic valves, Meccanica, Volume 50, Issue 5, pp 1387-1401, 2015. https://doi.org/10.1007/s11012-014-0097-5

[9] L. Marciniak, M. Banaś, J. Stryczek, The design and theoretical and experimental study of the plastic hydraulic valve, Proceedings of ASME 2016 9th FPNI Ph.D. Symposium on Fluid Power, p. 1-13, 2016. https://doi.org/10.1115/fpni2016-1511

[10] A. Milecki, A. Myszkowski, Modelling of electrohydraulic servo drive used in very low velocity applications. Int. J. Model. Identif. Control 7(3), 2009. https://doi.org/10.1504/ijmic.2009.027211

[11] A. Milecki, J. Ortmann, Electrohydraulic linear actuator with two stepping motors controlled by overshoot-free algorithm, Mechanical Systems and Signal Processing, vol. 96, p. 45-47, 2017. https://doi.org/10.1016/j.ymssp.2017.03.042

[12] B.K. Bose, Modern Power Electronics and AC Drives, 2002.

[13] Y. Kalaani,R. Haddad, A. E. Shahat, PMSM Sensorless Speed Control Drive, Journal of Engineering Research and Technology, vol. 1, issue 4, 2014.

[14] X. Zhang, G. H. B. Foo, A Constant Switching Frequency-Based Direct Torque Control Method for Interior Permanent-Magnet Synchronous Motor Drives, IEEE/ASME Transaction on Mechatronics, vol. 21, no. 3, p. 1445-1456, 2016. https://doi.org/10.1109/tmech.2015.2480782

[15] R.B. Walters, Hydraulic and Electro-Hydraulic Control Systems, Springer Netherlands, 2014.

[16] M. Stosiak, Vibration insulation of hydraulic system control components, Archives of Civil and Mechanical Engineering, Volume 11, Issue 1, p. 237-248, 2011. https://doi.org/10.1016/s1644-9665(12)60186-1

[17] N. Herakovic, Flow-Force Analysis in a Hydraulic Sliding-Spool Valve, Strojarstvo 51 (6) p. 555-564, 2009.

[18] J. F. Blackburn, Fluid Power Control, M. I. T. Press, 1960.

[19] D. Rybarczyk, A. Milecki, Modelling of an electrohydraulic proportional valve with a synchronous motor, Strojniski Vestnik/Journal of Mechanical Engineering, Vol. 61, Issue 9, 2015, p. 517-522. https://doi.org/10.5545/sv-jme.2015.2553

[20] D. Rybarczyk, D. Sędziak, P. Owczarek, and A. Owczarkowski, 'Modelling of Electrohydraulic Drive with a Valve Controlled by Synchronous Motor', in Progress in Automation, Robotics and Measuring Techniques, Cham, 2015, pp. 215-222. https://doi.org/10.1007/978-3-319-15796-2_22

[21] Bosch Rexroth, Proportional valve, from http:// www.boschrexroth.com/en/us/products/productgroups/industrial-hydraulics/proportional-and-servo-valves/, accessed Jan. 1, 2018.

[22] Moog, Direct drive valve, from http://www.moog.com/literature/ICD/Moog-Valves-D633_D634Catalog-en.pdf/, accessed Jul. 1, 2017.

[23] S. Ijaz, M. A. Choudhry, A. Ali, AND U. Javaid, Application of Fractional Order Control Technique to an Electro-Hydraulic Position Servomechanism, Mehran University Research Journal of Engineering \& Technology, .vol. 34, issue S1, August 2015.

[24] T. Sangpet and S. Kuntanapreeda, Force Control of an Electrohydraulic Actuator Using a FractionalOrder Controller, Asian Journal of Control, vol. 15, no. 3, p. 764-772, May 2013.

https://doi.org/10.1002/asjc.600 
[25] M. A. Luersena, b, R. Le Richec, Globalized Nelder-Mead method for engineering optimization, Computers \& Structures, Volume 82, Issues 23-26, September-October 2004, Pages 2251-2260. https://doi.org/10.1016/j.compstruc.2004.03.072

[26] M. Reza Faieghi, Abbas Nemati, On Fractional-Order PID Design, Applications of MATLAB in Science and Engineering, Prof. Tadeusz Michalowski (Ed.), 2011. https://doi.org/10.5772/22657

Submitted: $\quad 10.7 .2019$

Accepted: $\quad 03.02 .2020$
Dominik Rybarczyk

Andrzej Milecki

Institute of Mechanical Technology,

Poznan University of Technology,

Piotrowo 3, 60-965 Poznań, Poland 